\title{
Comparison of Body Temperature Between 5min and 10min Glass Mercury Thermometers in Under-5 Children in Axum Saint Mary Hospital, Central Zone of Tigray, Ethiopia
}

\author{
G. Hadgu ${ }^{1, *}$, S. Almaz ${ }^{2,3}$, R. Murugan ${ }^{2}$, S. Sisay ${ }^{4}$, A. Mebrahtu ${ }^{5}$, K. Gizenesh ${ }^{5}$, A. Teklit ${ }^{5}$, \\ G. Teklit ${ }^{5}$, S. Desta ${ }^{1}$, B. Zeray ${ }^{1}$, T. Lidya ${ }^{1}$, H. Geremedhin ${ }^{6}$ \\ ${ }^{1}$ School of Nursing, Axum University, Axum, Ethiopia \\ ${ }^{2}$ School of Nursing, Addis Ababa University, Addis Ababa, Ethiopia \\ ${ }^{3}$ Tikur Anbessa Specialized Hospital, Addis Ababa, Ethiopia \\ ${ }^{4}$ Department of Nursing, Mizan tepi University, Ethiopia \\ ${ }^{5}$ School of Public Health, Axum University, Axum, Ethiopia \\ ${ }^{6}$ School of Biomedical, Axum University, Axum, Ethiopia \\ *Corresponding author: hadguellen1@gmail.com
}

\begin{abstract}
Background: Evaluation of body temperature is one of the oldest known diagnostic methods and still an important sign of health and disease. Since rectal and oral temperature measurement are uncomfortable, less hygienic and unacceptable in many cultures; axillary has been method of choice in many countries like Ethiopia. In children decisions concerning investigation and treatment may base on results of temperature alone. Although accuracy of axillary temperature measurement is affected by a number of factors, device dwell time and device type are common. Objective: is to compare body temperature among 5 and 10 Min glass-mercury thermometer. Method: Experimental study design was used to compare body temperature among 5Minand 10Min GMT. A total of 98 samples were taken. The GMT ( 5 and $10 \mathrm{~min}$ ) was taken at the same axilla simultaneously. A statistical significance $(p<0.01)$ and clinical significant $\left(0.2^{\circ} \mathrm{C}\right)$ were used. Correlation and Bland-Altman plot were used to observe the agreements of the recording. Results: mean difference (MD) of 5 and10 GMT was $0.13673 \pm 0.13112$. A statistically significant difference was noted in comparisons of mean temperatures of 10min GMT with 5min GMT $(\mathrm{P}<0.000)$, But clinically not significant $\left(\mathrm{MD}<0.2^{\circ} \mathrm{C}\right)$. The correlation analysis also shows strong positive correlation $(\mathrm{r}>0.75)$ and all the MD were fall in the limit of agreement in Bland-Altman plot. Conclusion and Recommendations: Even a statistical significant $(\mathrm{p}<0.000)$ difference was observed in 5 min with 10min GMT the strong correlation, their good agreement and clinical insignificant, some important advantages of 5 Min GMT makes better than 10 Min. Their variation in temperature is not likely to change any clinical decision. So health professionals should use 5Min GMT for measuring body temperature in under-5 febrile illness except for neonate. Moreover researchers should repeat the study using core temperature as gold standard for comparison.
\end{abstract}

Keywords: body temperature, thermometers, mean difference, dwelling time, comparison

Cite This Article: G. Hadgu, S. Almaz, R. Murugan, S. Sisay, A. Mebrahtu, K. Gizenesh, A. Teklit, G. Teklit, S. Desta, B. Zeray, T. Lidya, and H. Geremedhin, "Comparison of Body Temperature Between 5min and 10min Glass Mercury Thermometers in Under-5 Children in Axum Saint Mary Hospital, Central Zone of Tigray, Ethiopia." American Journal of Medical Sciences and Medicine, vol. 5, no. 1 (2017): 10-19. doi: 10.12691/ajmsm-5-1-2.

\section{Introduction}

Body temperature is a measure of the body's ability to generate and get rid of heat. The normal physiology is to keep body temperature within a narrow safe range in spite of large variations in environmental temperatures. [1] Maintenance of body temperature occurs through the integration of multiple body systems that interact to maintain a balance between heat loss and generation.
Normal body temperature is around $37^{\circ} \mathrm{C}\left(98.6^{\circ} \mathrm{F}\right)$, but varies during the day. The lowest body temperature occurs in early morning hours ( $2 \mathrm{am}$ to $4 \mathrm{am}$ ) and the highest temperature occurs in the late afternoon. Body temperature may also increase as a result of overdressing or strenuous exercise, especially in hot weather. [2]

Fever is one of the body's normal defenses against attack from an infection or another disease. It is therefore a symptom, not a disease itself. A part of the brain that acts as the body's thermostat controls body temperature by balancing hot and cold signals throughout the body. Fever 
may actually play a role in fighting infections and shortening their course by turning on the body's immune system, thereby increasing the release and activity of white blood cells and other germ-killing substances. However, while some doctors recommend not treating fever, most do. This is because children are more likely to eat, drink and sleep if their body temperature is controlled. Not only reducing fever make they feel better, but also getting sick children to drink helps prevent dehydration. Although lack of fever does not rule out the presence of bacteria or other serious disease, high fever has a high correlation with serious illness. Febrile illness is defined as a disease characterized by an increase of body temperature more than $37.5^{\circ} \mathrm{C}$ resulting from infectious process. Febrile Illnesses (FIs) due to different etiologic agents are the most common causes of morbidity and mortality in developing tropical and subtropical countries. [3]

Many of the infectious diseases assessed, classified and treated using the Integrated Management of Childhood Illnesses (IMCI) guidelines have fever as a secondary cause. For example, many children with upper respiratory tract infection, pneumonia or ear infection will have fever. Severe illnesses associated with danger signs are also associated with fever, such as sepsis septicemia and meningitis. The danger signs lead to appropriate referral for the illness. Fever is also associated with malaria, dysentery and diarrhea in children. In these patients, the cause of the fever is treated and fever is not used in decision making. While these conditions all cause fever, the management of the condition itself results in the management of the fever. [4]

Body temperature in children can be measured at a number of anatomical sites using a range of different types of thermometers, including mouth, rectum and axilla. [5] Ideally, measurement should be reliable, non-invasive, non-traumatic, culturally acceptable, user-friendly and hygienic. Since rectal temperature measurements are relatively more time-consuming, invasive, uncomfortable, less hygienic and unacceptable in many cultures, and oral temperature is unhygienic and difficult in children, axillaries measurements have been the method of choice in many countries. $[6,7,8]$

Evaluation of body temperature is one of the oldest known diagnostic methods and is still an important sign of health and disease, both in everyday life and in medical care. The individual can describe feelings of illness and discomfort, but in conditions where individuals are unable to explain themselves e.g. children, the nurse has to interpret the clinical signs and rely on objective measurements. [9] Change in body temperature is one of the most important physical sign and symptom in both acute febrile illness as well as chronic illnesses in children. This is especially important in newborns, in which fever can be indicative of infection. It was shown that temperature out of the normal range is closely related to the survival of infants. [6,7,10,11] Many decisions concerning the investigation and treatment of children may based on the results of temperature measurement alone. [12,13]

As the basic sciences develop, temperature measurement methods and devices were improved. For hundreds of years, both in clinics and home, GMT was the standard of human temperature measurements [14] and currently developing countries are used it commonly, [15] though no longer recommended. [11,13,16,17,18,19]

Although accuracy of axillary temperature measurement is affected by a number of factors, including ambient temperature, local blood flows, inappropriate placing of the probe and closure of the axillary cavity, device dwell time and device type are common which can led to false high readings which may lead to expensive and painful diagnostic studies and medical interventions or false low readings which may lead to greater morbidity and mortality. So that temperature measurement must be accurate and consistent, as decisions about therapeutic intervention is based upon it. [9,20,21,22,23,24]

The accuracy of devices to record and grade temperature is uncertain.[1] Limited researches have been addressed whether the thermometer correctly identifies patients with hyperthermia or hypothermia. In general, these studies indicate that noninvasive temperature measurements are accurate in ruling out hyperthermia and hypothermia, but may fail to detect hyperthermia and hypothermia, depending on the dwelling time used.[25] So this study may feel the gap among health professionals.

Temperature taking is the most frequently performed clinical observation and is predominantly a nursing task. Although the use of digital thermometer is gradually increasing, MGT is still most common device used in the pediatric setting, especially in developing countries[15] in spite of having long dwelling time, danger of breakage, potential harm and toxic vapor effects; difficulties in reading, and possible role in spread of hospital acquired infections. [11,13,16,17,18,19,26] There is confusion about the proper length of time for waiting periods of MGT in axillary site. [27] Some studies highly recommend axillary MGT should wait 10Min rather than 5Min, which may be impractical, but other studies vice versa. Standard Nursing texts also vary between 5 and 10 Min which are not supported by current studies. [27]

It is important that the speed of application and ease of use does not prejudice a nurse's decision in choice of the thermometers and accuracy must be foremost consideration. Current nursing studies on temperature measurement are conducted to understand the efficacy of the various types of equipment available to measure temperature, [28,29] but they are insufficient and contradictory. Due to inconsistencies in both research methods and clinical practice [31,32] nurses are challenging in selecting the measurement method that is most appropriate for a patient and provides the most accurate and precise approximation of core temperature. [33]

The false low and false high result related to dwelling time may lead to misdiagnosis and treatment. Febrile illnesses are the most common leading cause of morbidity and mortality in under-5 children which needs accurate measurement of body temperature. Ethiopia is one of the developing countries which use GMT in measuring body temperature with the uncertainty of the dwelling time in their capability of detecting hyperthermia and hypothermia. So it is important to know the standard time to measure body temperature.

This study fills the gaps among health professionals and has some input on nursing body of knowledge. It will have contribution for decision makers and significant others to take possible measure on temperature measurement device. 
It will recommend possible solutions on dwelling time of GMT. It may decrease misdiagnosis of febrile illness in under-5 children related to inaccuracy of body temperature measurement due to dwelling time. This study will also be used as a base line data for further research on comparison of temperature measuring devices related topics. It is designed to compare dwelling time of 5Min and10Min MGT.

\section{Research Questions (Objective)}

Is there significant difference in body temperature result between 5Min and 10Min glass-mercury thermometers in Axillary site in Under-5 Children?

\section{Methodology}

\subsection{Study Area}

The study was carried out in Axum, city of northern Ethiopia, $1024 \mathrm{Km}$ north of Addis Ababa and $241 \mathrm{Km}$ far from Mekelle which is the capital city of Tigray region, located in the Central Zone of Tigray Region near the base of the Adwa mountains and surrounded by La'ilay Maychew woreda. Axum was the original capital of the kingdom of Axum and one of the oldest continuously inhabited places in Africa.

St. Marry hospital is one of the referral hospitals in the zone and FI is prevalent including ka-lazar, so that sample was found within the data collection period and at the time of my clinical experience, nurses working in the hospital and clinical students was debated regarding the devices even the controversy is as national. The qualified and trained health professionals may found in hospital than health center since accurate diagnosis of FI is needed. This is why the study focused on this area. Similarly as the generalizability is to the devices study area may not have effect.

According Köppen-Geiger climate classification system classifies its climate as subtropical highland. Having no great variation of environmental temperature may increase the validity of the result.

\subsection{Study Period}

The Study was conducted from November/2013 to May/2014.

\subsection{Study Design}

Experimental Study design was used to compare body temperature between 5Min mercury, 10Min mercury thermometers among under-5 children with FI using axillary site in Axum St. Marry hospital.

\subsection{Source and Study Population}

\subsubsection{Source Population}

The source population was all under-5 age children with FI visiting Axum St. Marry hospital for health care service.

\subsubsection{Study Population}

The study population was under-5 children with FI visiting Axum St. Marry hospital for health care service, particularly in under-5 OPD at the time of data collection.

\subsection{Inclusion and Exclusion Criteria}

\subsubsection{Inclusion Criteria}

Under-5 age children with FI

Children visiting Axum St. Mary hospital particularly under-5 OPD

\subsubsection{Exclusion Criteria}

Children under-5yrs of age with FI coming for follow up unless with new FI, children treated at ward and children under-5 with FI who have axillary ulcer, lethargy or unconscious, was excluded from the study as this have drawback for the study subjects and the study. As the sampling was convenience, irritable subjects were also excluded.

\subsection{Sample Size Determination}

A total of 96 samples was calculated using mean difference between 5Min and $10 \mathrm{Min}(0.27)$ and S.D 0.54 and 0.42 at alpha of 0.01 with detection capability (power) of $90 \%$ (beta 0.1 ) and taking 1 as ratio of exposed to non exposed using open epi statistical software. A total of 192 measurements was taken in both experimental and control group. Manually the study was also calculated using the following formula:

$$
\begin{gathered}
N=\frac{(r+1)\left(Z_{\alpha / 2}+Z_{1-\beta}\right) \sigma^{2}}{r d^{2}} \\
\mathrm{~N}=\frac{(1+1)(2.58+1.28)^{2} \cdot 4837^{2}}{1 * .27^{2}}=\frac{2 * 14.9 * 0.234}{1 * .073} \\
=\frac{6.972}{0.073}=95.5 \sim 96
\end{gathered}
$$

Where $r$ is the ratio of control to experimental which is $1: 1$ so $\mathrm{r}=1$

$\delta$ is the pooled standard deviation: 0.4837 , d is mean difference: 0.27

$\mathrm{Z}_{1-\beta}$ is normal deviated at $90 \%: 1.28$

$\mathrm{Z}_{\alpha / 2}$ is for $1 \%$ is 2.58 and $\mathrm{N}$ is sample size needed for each group.

\subsection{Sampling Procedures}

A convenient sampling procedure was used as the study conduct on Under-5 Children who are difficult in cooperating to the procedure. Since axillary movement will expose the mercury thermometer to the environment, which is easily affected by environmental temperature, children who were irritable were conveniently excluded from the study. All under-5 children with FI visiting under-5 OPD of St. Marry hospital who fulfills the inclusion criteria was taking until the sample size fulfill.

\subsection{Clinical Study Procedures}

Both the data collectors and participants were blinded to the control and experimental groups. 
The 5 and 10 Min GMT was in the same axilla with in the same time. The 5Min and 10Min GMT was the same thermometer except dwelling time difference.

The 5Min measurement GMT is the control group where as 10Min measurement of GMT is experimental group.

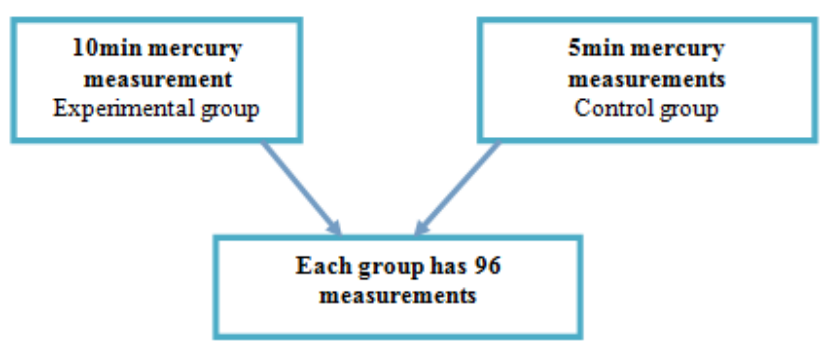

Figure 1. Diagrammatic presentation of clinical study procedure for comparison of body temperature among under-5 children with febrile illness by axillary site in Axum St. Marry hospital Tigray, Ethiopia, 2014GC

\subsection{Data Collection Procedures (Instrument, Personnel, Data Quality Control)}

The study was continuously collect primary data through data collection tools which is developed after review of literature and consultation with the experts in nursing. For content validity the tool was reviewed by experts. The tools included: Part-I: Demographic preformed, Part-II: Recording Temperature result and observation checklist. The demographic preformed was filled before starting the procedure.

The research data was collected on the same season and daily environment temperature was recorded. Data collection time was from 2:00-6:00 o'clock morning and 7:30-11:30 o'clock afternoon on local time. Any measurement result below 5Min and 10Min recommended for 5Min and 10Min measurement respectively due to irritability or other, even only for 10Min was discard. Data collectors record their measurements independently to avoid bias in reading the GMT. Each method was performed only one time on each study subject.

All data collectors(BSc Nurses) was screened for test of visual acuity in both eye 6/6 and trained thoroughly with close supervision for 4 days in correct positioning, calibration, reading of thermometers and documenting based on WHO guideline of taking axillary temperature. As these was particularly relevant concerning consistency and accuracy of measurement.All the temperatures was measured on the Celsius $\left({ }^{\circ} \mathrm{C}\right)$ scale and timed with the same stop clock.

The validity of the mercury-in-glass thermometers was ensuring by checking calibration. The mercury-in-glass bulb thermometers was shaken before each recording to decrease its temperature reading below $35^{\circ} \mathrm{C}$ and only those thermometers with a deviation of $0.1^{\circ} \mathrm{C}$ was used during temperature measurement. If the thermometers were not calibrated, they were not meeting their potential to examine the research question and hypothesis. In an effort to avoid this threat to validity, calibration was addressed according to individual thermometer manufacturer instructions.

In addition, prior to data collection 5 mercury thermometers were left for $5 \mathrm{Min}$ in water bath three times. Of these the four thermometers that results the same value was used.
Drying of axillary site was also construct validity for the study. This study was performing measurements following manufacturer information for each of the thermometry instruments, as described in the instruments and measurements section.

One GMT was used for 5Min and 10Min GMT to avoid instrumental bias. First GMT was calibrated below $35^{\circ} \mathrm{C}$ then the GMT result of $5 \mathrm{~min}$ was recorded after $5 \mathrm{~min}$. 10min GMT was taking by adding $5 \mathrm{~min}$ without calibration of 5min GMT result. The data on temperature measurement was collected in two phase. Phase one was pre-test study conducted at Axum health center involving 10 children with FI to determine the selection methods of participants, the adequacy of parent's information sheet and consent form, and to check the thermometer functioning correctly. Phase two involves collecting the data in the study area.

\subsection{Operational Definitions}

Febrile Illness: A disease characterized by increase body temperature more than $37.5^{\circ} \mathrm{C}$ resulting from infectious process like malaria, pneumonia, measles, otitis media, acute gastro-enteraites, upper respiratory tract infection, meningitis...

Clinical Significance of Temperature: The mean difference of temperature result between $5 \mathrm{Min}$ and 10Min mercury thermometer or mercury and digital is $\geq 0.2^{\circ} \mathrm{C}$.

Body Temperature: It is the degree of heat maintained by the body or it is the balance between heat produced in the tissues and heat lost to the environment.

Body Temperature Result: Temperature results from axillary site using GMT.

Normal Body Temperature: Axillary body temperature between is $36.5-37.5^{\circ} \mathrm{C}$ using GMT

Pyrexia: Axillary body temperature ranges $37.5-40^{\circ} \mathrm{C}$ using GMT or DT

Hyper pyrexia: Axillary body temperature $40^{\circ} \mathrm{C}$ and above using GMT or DT

Hypothermia: Axillary body temperature less than $36.5^{\circ} \mathrm{C}$

\subsection{Variables}

\subsubsection{Dependent Variables}

The dependent variable is body temperature result of GMT.

\subsubsection{Independent Variables}

Demographic variables: Age, sex, religion,

Temperature variation variables: Dwelling time of GMT (5Min and 10Min) are the study variables

Co-variant variables: Route (site) of measurement, Right and lift axilla, placement of probe, environment, local blood flow, closure of axilla, taking antipyretic medication, taking bath with in 30Min, time (morning, afternoon), and type of FI.

\subsection{Scale of Measurements}

For body temperature, degree celliuse scale of measurement was used in both GMT. For time, in GMT, minute was scale of measurement. 


\subsection{Data Analysis Procedures}

First the data was interred and coded to epi info version 3.54 and exported to analysis in SPSS version 21 window7. Data analysis included descriptive statistics was used to describe participants' demographic characteristics and temperature result (hypothermia, normal, pyrexia, and hyper pyrexia) by percentage, mean, standard deviation and range. Correlation was determined by the Pearson correlation coefficient (to determine the strength of the correlation) while the extent of agreement was assessed with the Bland-Altman plot. To determine statistically significant difference a paired t-tests was used; $\mathrm{p}<0.01$ was statistically significance. Not only statistical, clinical significance was also considered in the analysis. Even though the Standard clinical significance varies with different literatures most of them use a mean difference of $0.2^{\circ} \mathrm{C}$ as not clinical significance. This study was also used mean difference $0.2^{\circ} \mathrm{C}$ between control and experiment group was clinical significant.

\subsection{Data Quality Management}

Visual acuity and training for data collectors about filling the socio-demographic information and taking the axillary temperature procedure was done to help for the quality of data. Drying axillary site and taking temperature at the same time was considered to have some input on the quality of data. Similarly, pilot study and exclusion of thermometers having difference was carried out prior to data collection.

Content validity was checked by experts and close supervision during data collection procedure and proper recording was also taken. Immediate checkup was carried out and any unfulfilled data was filled immediately. The study design also overcomes methodological difficulties encountered by previous experimental studies:

1. Use of one axilla for 5Min and 10Min GMT

2. Addition of $5 \mathrm{~min}$ for $10 \mathrm{~min}$ GMT without calibration of $5 \mathrm{~min}$ GMT result

\subsection{Ethical Considerations}

Institution Review Board (IRB) of Addis Ababa University, College of Health Science, School of Allied Health Sciences, Department of Nursing and Midwifery was review the protocol to insure full protection of the rights of study subjects. Following the approval by IRB, Official letter of co-operation was written to Axum St. Marry hospital from Department of Nursing and Midwifery of AAU. After getting permission from Axum St. Marry hospital, data collectors was inform to parents verbally and at least one parent was present during the data collection. Data was treated confidentially and identify subject by number only. Since it is axillary, it is safe and measurementswere taken at OPD during assessment and also take 10Min for all measurement.So it has no treatment and investigation delay. As the sampling is convenience, irritable subjects were also not forced. Risk of skin irritation was informed with informed consent. Any breakage of GMT was disposed appropriate as it is environmental hazard. Probe was cleaned according to service manual instructions (WelchAllyn,
Inc.) prior to use for individual study subject as this prevents risk of infection.

\section{Result}

\subsection{Socio-Demographic}

A total 100 study subjects were collected. Of these 2 were excluded from the analysis due to their incompleteness and unreadable in their temperature result. A total of 98 study subject were analyzed. 66(67.3) were collected in the morning. Of the 98, 53(54.1\%) were female. 90(91.8) were orthodox.34(34.7\%) were aged from 1-3Yrs. For detail see Table 1.

96 and 90 of the respondents were not taking bath and antipyretic within 30min prior to data collection respectively. 35 were diagnosis with pneumonia. For detail see Figure 2.

\subsection{Temperature Results}

In this study one reading each with the $5 \mathrm{~min}$ glass mercury thermometer, 10min glass mercury thermometers were taken for each patient.The procedure was carried out for 98 subjects. This resulted in $985 \mathrm{~min}$ mercury temperature readings and10min mercury temperature readings. The mean temperature of $5 \mathrm{~min}$ mercury thermometer, 10min mercury thermometer and digital were $37.29 \pm .77,37.43 \pm .77$ and $37.3 \pm .78$ respectively. For detail seen Table 2 .

The maximum difference of the 5 min mercury with 10 min mercury readings was 0.6 . The minimum difference was $0.10^{\circ} \mathrm{C}$. Only 19 have no difference with $10 \mathrm{~min}$ GMT.

Table 1. Frequency and percentage of socio-demographic characteristic of under-5children with febrile illness in under-5 OPD of Axum St. marry hospital, Tigray, Ethiopia from 22-29/8/ 2014G.C

\begin{tabular}{|c|c|c|c|}
\hline S. No & Variables & Frequency & Percentage \\
\hline \multirow[t]{5}{*}{1} & Age & & \\
\hline & 0 -28 days & 4 & 4.1 \\
\hline & 29days-1Yrs & 30 & 30.6 \\
\hline & 1-3Yrs & 34 & 34.7 \\
\hline & 3-5Yrs & 30 & 30.6 \\
\hline \multirow[t]{3}{*}{2} & Sex & & \\
\hline & Male & 45 & 45.9 \\
\hline & Female & 53 & 54.1 \\
\hline \multirow[t]{3}{*}{3} & Religion & & \\
\hline & Orthodox & 90 & 91.8 \\
\hline & Muslim & 8 & 8.2 \\
\hline \multirow[t]{5}{*}{4} & Care giver & & \\
\hline & Mother & 86 & 87.8 \\
\hline & Father & 7 & 7.1 \\
\hline & Sister/brother & 2 & 2 \\
\hline & Care servant & 3 & 3.1 \\
\hline
\end{tabular}


Only 14(14.3\%) of the 98 paired measurements of each 5min GMT and 10min GMT have temperature difference greater than $0.2^{\circ} \mathrm{C}$. For detail see Table 3 .

The frequency and percentage of grading fever for each thermometer are shown in Table 4.

The mean difference of $10 \mathrm{~min}$ and $5 \mathrm{~min}$ GMT was $0.13673 \pm 0.13112$.

\subsection{Statistical Results}

A statistically significant difference was noted in comparisons of mean temperatures of 10min GMT with 5min GMT $(\mathrm{P}<0.000)$, but there were no clinical differences (defined as a mean difference of $0.2 \mathrm{C}$ ). For detail see Table 5 .

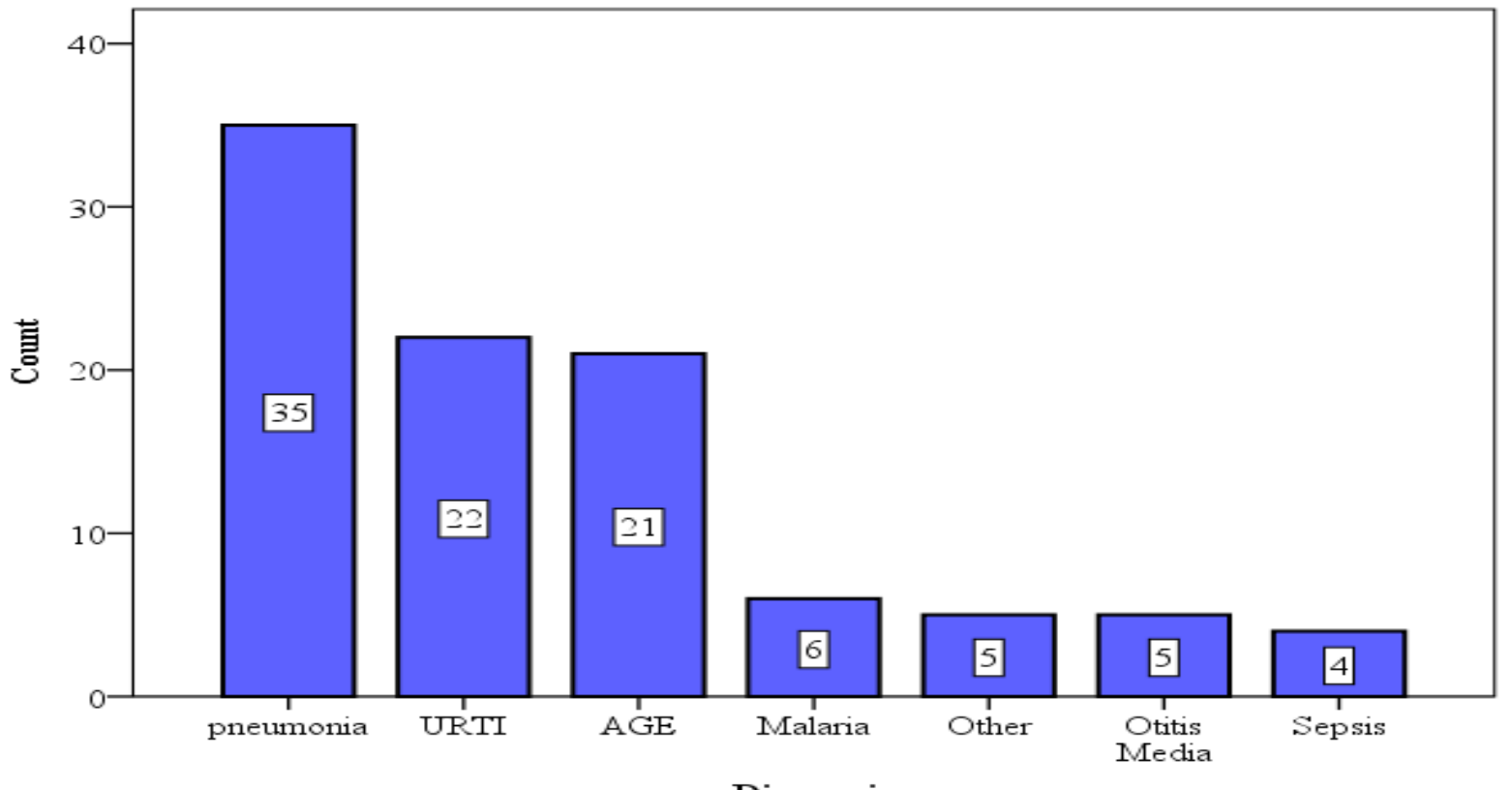

Figure 2. count of diagnosis of under-5 children with febrile illness in under-5 OPD of Axum St. marry hospital, Tigray, Ethiopia from 22-29/ 8/2014G.C

Table 2. Mean, SD and Range of Temperature Result of 5Min GMT, 10Min GMT and DT among Under-5yrs of age Children with FI visiting Under-5 OPD in Axum St. Marry hospital, Tigray, Ethiopia from 22-29/8/ 2014G.C

\begin{tabular}{|c|c|c|c|c|c|c|}
\hline Thermometers & Observation & Mean \pm SD & Median & Range & Minimum & Maximum \\
\hline 5Min Mercury & 98 & $37.29 \pm .77$ & 37.2 & 4 & 35.6 & 39.6 \\
\hline 10Min Mercury & 98 & $37.43 \pm .77$ & 37.4 & 3.7 & 35.9 & 39.6 \\
\hline
\end{tabular}

Table 3. Difference of Temperature in ${ }^{\circ} \mathrm{C}$ and Frequency between 5Min GMT and 10Min GMT among Under-5yrs of age Children with FI visiting Under-5 OPD in Axum St. Marry hospital, Tigray, Ethiopia from 22-29/8/ 2014G.C

\begin{tabular}{|l|c|c|}
\hline Comparisons & Difference of Temperature in OC & Frequency of Difference n (\%) \\
\hline \multirow{2}{*}{ 5Min and 10Min Mercury } & No & $19(19.4)$ \\
\cline { 2 - 3 } & 0.1 & $35(35.7)$ \\
\cline { 2 - 3 } & 0.2 & $30(30.6)$ \\
\cline { 2 - 3 } & $>0.2$ & $14(14.3)$ \\
\hline
\end{tabular}

Table 4. Frequency of Grading Fever by Thermometers among Under-5yrs of age Children with FI visiting Under-5 OPD in Axum St. Marry hospital, Tigray, Ethiopia from 22-29/8/ 2014G.C.

\begin{tabular}{|c|c|c|c|c|}
\hline & \multicolumn{3}{|c|}{ Frequency (Percentage) of Grading of Fever } \\
\hline Thermometers & Hypothermia & Normal & Pyrexia & Hyper pyrexia \\
\hline 10Min Mercury & $8(8.2)$ & $44(44.9)$ & $4(46.9)$ & $43(43.9)$ \\
\hline 5Min Mercury & $10(10.2)$ & $45(45.9)$ & $0(0)$ \\
\hline
\end{tabular}

Table 5. Statistical values among Comparison Groups (5Min and10Min GMT) among Under-5yrs of age Children with FI visiting Under-5 OPD in Axum St. Marry hospital, Tigray, Ethiopia from 22-29/8/ 2014GC

\begin{tabular}{|c|c|c|c|c|c|}
\hline \multirow{2}{*}{ Comparison Groups } & Mean difference \pm SD & t-cal & \multicolumn{2}{|c|}{ P-value } & \multicolumn{2}{|c|}{ L9\% CI of the Mean difference } \\
\cline { 3 - 5 } & & & 10.323 & 0 & 0.10193 \\
\hline
\end{tabular}


Table 6. Statistical values of comparison groups in relation to socio-demographic and other variables among Under-5yrs of age Children with FI visiting Under-5 OPD in Axum St. Marry hospital, Tigray, Ethiopia from 22-29/8/ 2014GC

\begin{tabular}{|c|c|c|c|c|}
\hline \multirow{2}{*}{ S. $N$} & \multirow{2}{*}{ Variables } & \multirow{2}{*}{ Observation } & \multicolumn{2}{|c|}{5 Min and10 Min GMT } \\
\hline & & & $\mathrm{MD} \pm \mathrm{SD}$ & P-value \\
\hline \multirow[t]{5}{*}{1} & Age & & & \\
\hline & 0-28days & 4 & $-0.225 \pm 0.126$ & 0.037 \\
\hline & 29days- 1yr & 30 & $0.133 \pm 0.177$ & 0 \\
\hline & 1-3Yrs & 34 & $-0.12 \pm 0.12$ & 0 \\
\hline & 3-5Yrs & 30 & $-0.15 \pm 0.086$ & 0 \\
\hline \multirow[t]{3}{*}{3} & \multicolumn{3}{|c|}{ Time of Measurement } & \\
\hline & Morning & 67 & $-0.14 \pm 0.1$ & 0 \\
\hline & Afternoon & 31 & $-0.135 \pm 0.18$ & 0 \\
\hline \multirow[t]{3}{*}{5} & \multicolumn{3}{|c|}{ Taking antipyretic } & \\
\hline & Yes & 8 & $-0.15 \pm 0.09$ & 0.003 \\
\hline & No & 90 & $-0.135 \pm 0.134$ & 0 \\
\hline \multirow[t]{3}{*}{6} & \multicolumn{2}{|c|}{ Axillary } & & \\
\hline & Rt GMT and Lt DT & 49 & & \\
\hline & Lt GMT and Rt DT & 49 & & \\
\hline
\end{tabular}

Statistical analysis in relation to socio-demographic and other was done but no difference was observed clinically and statistically except for neonatal in which clinical significance (0.225) was observed though not statistically significant. This is most probably due to few observations. See the Table 6 .

\subsection{Correlation Analysis}

In all the comparisons groups they have strong positive correlation. The Pearson correlation(r) of $5 \mathrm{Min}$ and 10 min GMT was 0.99 which implies both as the result of 5GMT increases the result of 10 GMT also increase.
Both have direct positive relation. For further see the Table 7.

Table 7. Correlation ${ }^{\circledR}$ among Comparison Groups (5Min with10Min GMT) among Under-5yrs of age Children with FI visiting Under-5 OPD in Axum St. Marry hospital, Tigray, Ethiopia in 2014GC

\begin{tabular}{|c|c|c|}
\hline Thermometers & 5min GMT & 10min GMT \\
\hline 5min GMT & 1 & \\
\hline 10min GMT & 0.99 & 1 \\
\hline
\end{tabular}

The graphic representation of the correlation was shown in Figure 3.

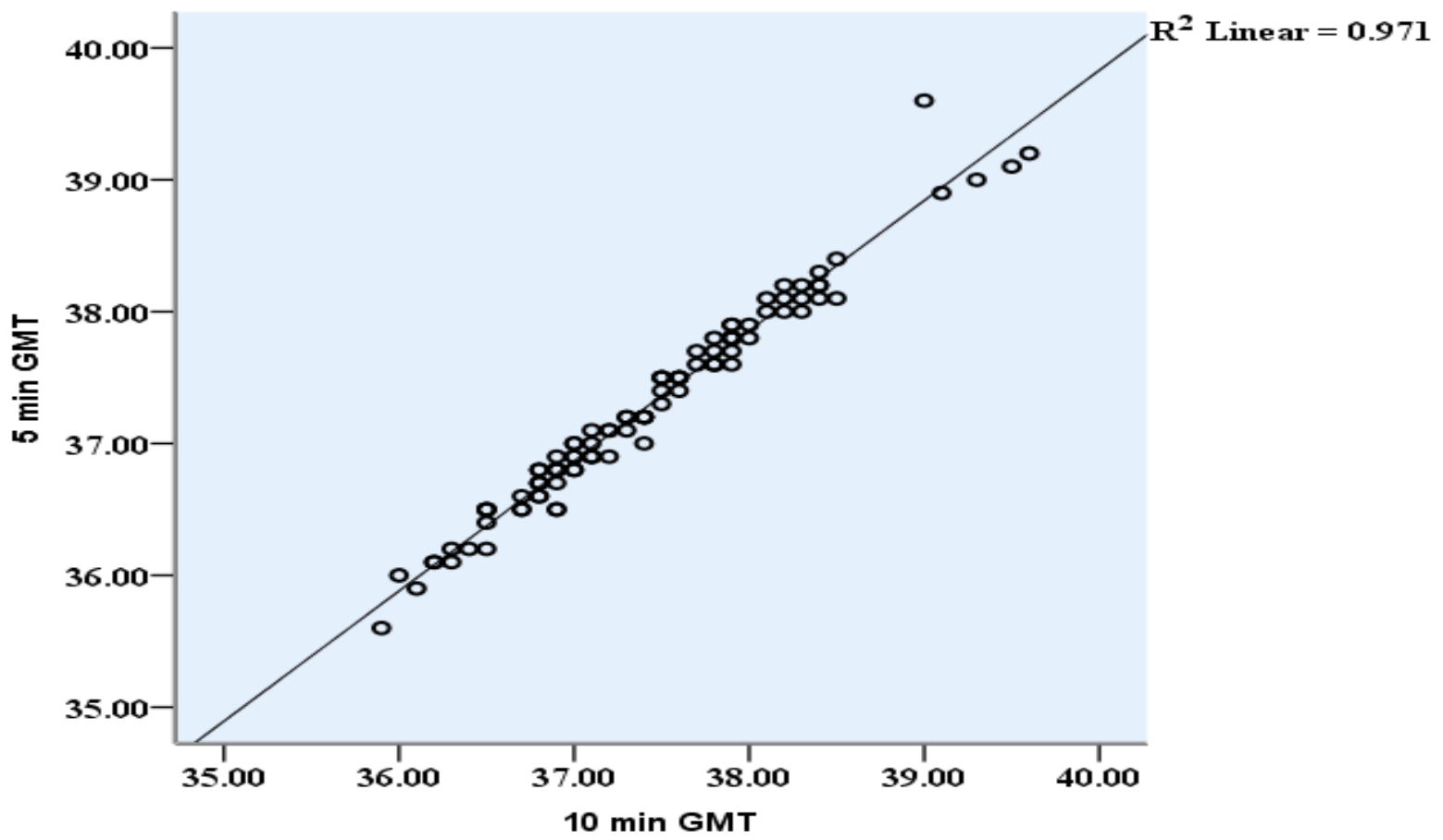

Figure 3. Correlation of 5min GMT with 10min GMT 


\subsection{Band-Altman Analysis}

In order to determine the concordance between the glass- mercury thermometer and the digital thermometer, the Bland Altman method of analysis was used.

Figure 4 depicts the Bland Altman plot of the 10min mercury temperature readings and $5 \mathrm{~min}$ mercury temperature readings.It shows all of the readings were falling within the lines of limits of agreement i.e upper limit of 0.475 and lower limit of -0.2016 and Only 1 readings were falling outside the lines of limit which is outlier observed in the above. The limit of agreement is 0.1367 . The positive sign and becoming all the mean difference above direct line (0.0) except the12 mean difference which are in the direct line $(0.0)$ indicates $10 \mathrm{~min}$ is sensitive than $5 \mathrm{~min}$ GMT. A value of zero implies perfect concordance.

The horizontal line in the middle indicates the mean difference of two measurements, and two additional lines indicate $2.58 \mathrm{SD}$ above and below the mean.

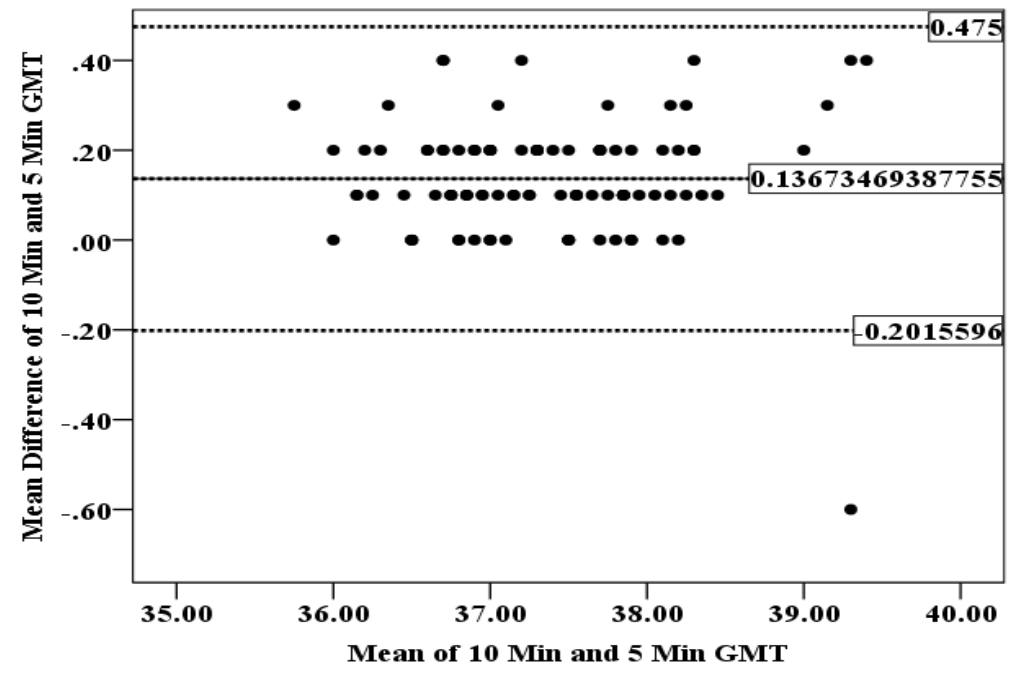

Figure 4. Bland-Altman plot of 5min GMT and 10min GMT

5min GMT was agree with 10min GMT 93 of 98 measurements in grading fever. For detail see Table 8.

Table 8. Agreement of 10Min GMT with $5 \mathrm{~min}$ GMTin Specific Range of Temperature among Under-5yrs of age Children with FI visiting Under-5 OPD in Axum St. Marry hospital, Tigray, Ethiopia in 2014GC

\begin{tabular}{|c|c|c|c|c|}
\hline \multirow{2}{*}{} & 10Min GMT & \multicolumn{3}{c|}{ Temperature Results in oC } \\
\cline { 3 - 5 } 5Min GMT & $<36.5$ & $36.5-37.5$ & $\geq 37.5$ \\
\hline \multirow{3}{*}{$\begin{array}{c}\text { Temperature } \\
\text { Results in }{ }^{\circ} \mathrm{C}\end{array}$} & $\begin{array}{c}36.5- \\
37.5\end{array}$ & 0 & 2 & 0 \\
\cline { 2 - 5 } & $>=37.5$ & 0 & 42 & 3 \\
\cline { 2 - 5 } & $>36.5$ & 0 & 43 \\
\hline
\end{tabular}

Clinical implications: the numerical value represents number of recording in each category. The shaded area represents agreement for that specific temperature range.

\section{Discussion and Conclusion}

\subsection{Discussion}

Temperature is one of the most common and important clinical sign. The gold standard for ambulatory patient temperature recording has been done by the clinical mercury thermometer. Due concerns about the breakages and environmental hazards newer thermometers have evolved with the hope of replacing the clinical mercury thermometer. The present study was conducted to find the concordance of the digital thermometer with the clinical mercury thermometer. The variability of GMT placement time and importance of speed of application and ease of use was important in busy clinical area, but accuracy must be primary concern.

In this study, statistical test, correlation, and clinical significant were used to compare the dwelling time and device. Bland-Altman analysis was also used as it is necessary to establish agreement between the thermometer recordings.

In this study the dwelling time of GMT (5min and $10 \mathrm{~min})$ was statistically significant $(\mathrm{p}<0.00)$ which is comparable with the studies conducted in Turkey $(\mathrm{P}<0.05$, 27), Korea $(\mathrm{P}<0.05,44)$, China $(\mathrm{P}<0.001,45)$, and Canada (19). Similarly a systematic review conducted by Craig, 2000 [1a] (43) demonstrates the longer placement time for axillary thermometers the increase accuracy of the temperature measurement (47), but studies from china and India shows not statistical significant $(\mathrm{P}>0.05) 40-41$. This may be due to narrow dwelling time ( $5 \mathrm{~min}$ with $8 \mathrm{~min}$ ), (6min with $10 \mathrm{~min}$ ), study subjects were non-febrile (normal) in which the sensitivity of GMT may differ and body temperature may have variation within $10 \mathrm{~min}$ difference as $10 \mathrm{~min}$ GMT was taken after $6 \mathrm{~min}$ with calibration unlike this study.

The study also shows 10min GMT is sensitive than $5 \mathrm{~min}$ GMT since no mean difference value is below 0.0 in Bland -Altman plot Figure 4 But clinically $5 \mathrm{~min}$ and 10 min GMT shows no significance difference since mean difference was $0.1367 \pm 0.13112$ which is less than $0.2^{\circ} \mathrm{c}$. Similarly 5min GMT and 10min GMT shows strong positive correlation ( $\mathrm{r}=0.99$ ).

The analysis of limits of agreement by Bland-Altman method indicates the 99\% CI of the mean difference was 0.10193 and 0.17154 with mean difference of0.1367. All of the readings were falling within the lines of limits of 
agreement i.e upper limit of 0.475 and lower limit of -0.2016 except the out liar. 99\% CI the mean difference was among 0.1 and above $0.172^{\circ} \mathrm{C}$ which is not clinically significant difference. Mean difference of $5 \mathrm{~min}$ and $10 \mathrm{~min}$ GMT of neonates' shows clinical significant but this is probably due to few observations. Both GMT 93 of 98 observed records were agreed in specific range of temperature.

Due to environmental hazarids and risk of breakage GMT are currently not recommended but the concordance of GMT with Digital mercury are unclear Except study conducted in Tikur Anbessa Specialized Hospital shows no clinical significance. [48]

\subsection{Strength and Limitation of the Study}

\subsubsection{Strength}

Recording the temperature of GMT at the same time and recording 10min GMT without calibration of $5 \mathrm{~min}$ GMT was some strength of the study.

Prior to data collection the instruments used were tested their reliability and validity.

Use of multi-dimensional analysis (paired t-test, correlation, Bland-Altman, clinical significance) makes the result more conclusive.

\subsubsection{Limitation}

The concordance of the instruments was limited for febrile illness so the generality could not include in detecting hypothermia as the study subjects was selected based on their diagnosis.

The study did not use a core temperature as gold standard for comparison.

The clinical significant observed in neonatal was may be related to few observation and the cut point of clinical significant $\left(0.2^{\circ} \mathrm{C}\right)$ was not representative.

\subsection{Conclusion and Recommendation}

\subsubsection{Conclusion}

Even a statistical significant $(\mathrm{p}<0.000)$ difference was observed in $5 \mathrm{~min}$ and 10min GMT their mean difference was not clinically significant $\left(<0.2^{\circ} \mathrm{C}\right)$ or do not differ enough to cause problems in clinical interpretation then the device could be used interchangeably. Their correlation was also strong positive correlation $(r>0.75)$ and all the mean differences among them were fall in the limit of agreement in Bland-Altman plot. As luck of consistent mean difference (homogeneous variation) between GMT was shown and their difference was clinically not significant, no compensation for the difference is needed.

Generally the strong correlation, their good agreement, their clinical insignificant, some important disadvantages of 10 min GMT such as danger of breakage, potential harm and toxic vapor effects; long dwelling time and some important advantage of $5 \mathrm{~min}$ GMT such as rapid result delivery, makes $5 \mathrm{~min}$ GMT good alternative to the 10 min glass mercury thermometer.

\subsubsection{Recommendation}

Health professionals should use 5 min GMT for measuring body temperature in under-5 febrile illness except for neonate.
Moreover researchers should repeat the study by using core temperature as gold standard for comparison.

\section{References}

[1] Shaheed.J, Rahman N, Kasem FB, Islam MR, Sultana R, A.M: Comparison Between Mercury and Liquid Crystal Forehead Thermometers for Measurment of Body Temperature. Suhrawardy Med Coll. 2012; 4(2): 60-1.

[2] Holtzclaw, B.J Circadian rhythmicity and homeostatic stability in thermoregulation. Biological Research for Nursing, 2001; 2: 22135.

[3] Abyot Bekele Woyessa, Worknesh Ayele, Abdi Ahimed, Nega: A. Investigation of acute febrile illness outbreakAsyaita and Dupti districts, Afar Region, Ethiopia. bmj. February 2011; 9 (Suppl 1): 46.

[4] World Health Organization (WHO) Department of Child and Adolescent Health and Development (CAH). Technical seminar other causes of fever, 1-5.

[5] Ng D, Lam J, Chow K. Childhood fever revisited. Hong Kong Medical journal= Xianggang yi xue za zhi/Hong Kong Academy of Medicine. 2002;8(1):39.

[6] Çultu Ö, Yildirim I, Ceyhan M, Korkmaz A, Yurdakök M, Karaagaoglu E, et al. Comparing body temperature measurements by Mothers and physicians using mercury-in-glass, digital mercury and infrared tympanic membrane thermometers in healthy newborn babies. Turk J Pediatr. 2008; 50: 354-8.

[7] Zeal JD, Consultants C: ThermoSpot-a non-invasive hypothermia indicator for neonates, infants and children.

[8] Mehreen Adhi, Rabia Hasan, Fatima Noman, Syed Faisal Mahmood, Anwar Naqvi, Adib-ul-Hasan Rizvi: Range for Normal Body Temperature in the General Population of Pakistan, 2008; 58(10).

[9] Märtha Sund-Levander: Measurement and Evaluation of Body Temperature, Implications for Clinical Practice. [dessertation]. 2004(872).

[10] Bailey J, Rose P. Axillary and tympanic membrane temperature recording in the preterm neonate: a comparative study. Journal of advanced nursing. 2001; 34(4): 465-74.

[11] Chung W, Chen C. Evaluation of performance and uncertainty of infrared tympanic thermometers. Sensors. 2010; 10(4): 3073-89.

[12] El-Radhi A, Barry W. Thermometry in paediatric practice. Archives of disease in childhood. 2006; 91(4): 351-6.

[13] Fadzil FM, Choon D, Arumugam K. A comparative study on the accuracy of noninvasive thermometers, Australian family physician. 2010; 39(4): 237-9.

[14] Devrim I, Kara A, Ceyhan M, Tezer H, Uludağ AK, Cengiz AB, et al. Measurement accuracy of fever by tympanic and axillary thermometry. Pediatr Emerg Care. 2007; 23(1): 16-9.

[15] Benkovich N, Farrell BC, Nimunkar A, Baran J, Webster JG. Low Cost Digital Thermometer. 2009.

[16] Dolkar R, Kapoor S, Singh NV, Suri V. A comparative study on the recording of temperature by the clinical mercury thermometer and digital thermometer, Nursing and Midwifery Research, 2013; 9(1): 40-6.

[17] Gasim GI, Musa IR, Abdien MT, Adam I. Accuracy of tympanic temperature measurement using an infrared tympanic membrane thermometer, BMC research notes, 2013; 6(1): 194.

[18] ByadMinon, editor. Best Infant Thermometers,Tympanic Thermometersk, August 17, 2013.

[19] Y vonne M. Shevchuk B, PharMD, FCSHP. chapter-9 fever. 85-92.

[20] Pušnik I, Miklavec A. Dilemmas in measurement of human body temperature. Instrumentation Science and Technology, 2009; 37(5): 516-30.

[21] Schmitz T, Bair N, Falk M, Levine C. A comparison of five methods of temperature measurement in febrile intensive care patients, American journal of critical care. 1995; 4(4): 286-92.

[22] McCallum L, Higgins D. Measuring body temperature, Nursing Times. 2012; 108(45): 20-2.

[23] Jeanette Grady. Nursing Procedure: Measuring and Monitoring Temperature in the Highly Dependent or Critically Ill Infant or Child - Axilla temperature review. 
[24] Smith LS. Reexamining age, race, site, and thermometer type as variables affecting temperature measurement in adults- $\mathrm{A}$ comparison study. BMC nursing. 2003; 2(1): 1.

[25] Elizabeth Bridges and Karen Thomas Noninvasive measurement of Body Temperature in Critically Ill. CriticalCareNurse. JUNE 2009; 29(3): 97.

[26] Rosenthal HM, A. L. Measuring temperature of NICU patients-A comparison of three devices. J Neonatal Nurs. 2006; 12: 125-9.

[27] Khorshid L, Eşer İ, Zaybak A, Yapucu Ü. Comparing Mercuryinglass, tympanic and disposable thermometers in measuring body temperature in healthy young people. Journal of clinical nursing. 2005; 14(4): 496-500.

[28] Sganga A, Wallace R, Kiehl E, Irving T, Witter L. A comparison of four methods of normal newborn temperature measurement. MCN: The American Journal of Maternal/Child Nursing. 2000; 25(2): 76-9.

[29] Uslu S, Ozdemir H, Bulbul A, Comert S, Bolat F, Can E, et al. A comparison of different methods of temperature measurements in sick newborns, Journal of tropical pediatrics. 2011; 57(6): 418-23.

[30] Arslan GG, Eser I, Khorshid L. Analysis of the effect of lying on the ear on body temperature measurement using a tympanic thermometer Analysis, 2011.

[31] Cassandra Sutton S, Year 2 Issue: Oral versus axilla temperature measurement [a review of the evidence]. Tasmania: Tasmanian School of Nursing Nuritinga 1999.

[32] Davies, S.P, Kassab, J.Y., T hrush, A.J. aS, et al. A comparison of mercuryand digitalclinical the rmomete rs. J A dvancedNurs, 2006; 11(5): 535-43.

[33] Lawson L, Bridges EJ, Ballou I, Eraker R, Greco S, Shively J, et al. Accuracy and precision of noninvasive temperature measurement in adult intensive care patient. American journal of critical care. 2007; 16(5): 485-96.

[34] Cutter J. Recording patient temperature--are we getting it right? Professional nurse (London, England). 1994; 9(9): 608-10, 12, 15-6.

[35] Potter PA, Perry AG, Hall A, Stockert Patricia A. Fundamentals of nursing: Elsevier Mosby; 2009.

[36] Fulbrook P. Core temperature measurement in adults: a literature review. Journal of advanced nursing. 1993; 18(9): 1451-60.
[37] Ulusoy MF \& Go"rgu "lu " R. Hems, irelik Esaslar1-Temel Kuram Kavram_ Ilke ve Yo "ntemler, Cilt TDFO Ltd S,ti,Ankara,. 1996; 1(2. bs. 72 ): 151-3.

[38] Haddadin R. Study between axillary and rectal temperature measurements in children. Eastern Mediterranean health journal. 2007; 13(5): 1060-6.

[39] Roy AS, Chowdhury T, Bandhopadhya D, Ghosh G. Time required to document temperature by electronic skin thermometer in a healthy neonate. Indian pediatrics. 2009; 46(12): 1103.

[40] Deorari A. Neonatal hypothermia In Newborn Care Practice and Care Settings. 2004: 65-71.

[41] Yu-qin Z. sududy on accuracy of three different time to obtain readings in measuring axillary temperature. Journal of Clinical Nursing. 2007; 1.

[42] Chaturvedi D, Vilhekar K, Chaturvedi P, Bharambe M. Comparison of axillary temperature with rectal or oral temperature and determination of optimum placement time in children. Indian pediatrics, 2004; 41(6): 600-4

[43] Greyling G, Viljoen M, Joubert G. Axillary temperature compared to tympanic membrane temperature in children] Curationis, 2000; 23(3): 54.

[44] JI He Journal Editorial Staff of Henan University Kaifeng KaiFeng 475001, China. The Study on Different time to Take Temperature in Axillary, China Foreign Medical Treatment. ; 2009; 29.

[45] Sheng L, Heping C, Qinfang Z. Probe into measuring time of auxillary temperature for patients,Chinese General Nursing. 2008; 33: 002.

[46] Li Shu-Ying, Lin Min, Huang Cai-hui. Research and practice of axillary temperature measurement at interval. Journal of Henan University(Medical Science), 2012; 01.

[47] Craig JV, Lancaster GA, Wasiamson PR, Smyth RL. Temperature measured at the axilla compared with rectum in children and young people: systematic review. BMJ: British Medical Journal, 2000; 320(7243): 1174.

[48] Hadgu Gerensea and Rajalakshmi Murugan, "Is There Significant Difference between Digital and Glass Mercury Thermometer?," Advances in Nursing, vol. 2016, Article ID 3474503, 10 pages, 2016. 